E3S Web of Conferences 1, 41013 (2013)

DOI: $10.1051 / \mathrm{e} 3$ sconf/ 20130141013

(C) Owned by the authors, published by EDP Sciences, 2014

\title{
Risk Assessment of Contamination by Heavy Metals in Zanjan of Iran using SAW method
}

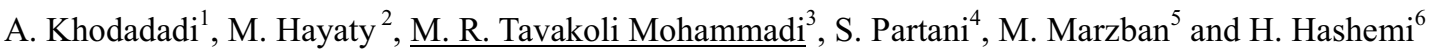 \\ ${ }^{1}$ Assoc. Prof. of Environmental Engineering, Modares Environmental Research Center (MERC), Tarbiat Modares \\ University, Tehran, Iran \\ ${ }^{2} \mathrm{PhD}$ Student of Mining Engineering, Sharood University of Technology, Sharood, Iran \\ ${ }^{3} \mathrm{PhD}$ Student of Mining Engineering, Tarbiat Modares University, Tehran, Iran \\ ${ }^{4} \mathrm{PhD}$ Student of Civil Engineering, Tarbiat Modares University, Tehran, Iran \\ ${ }^{5}$ Msc Student of Mineral Processing, Tarbiat Modares University, Tehran, Iran \\ ${ }^{6}$ Msc Student of Civil Engineering, Tarbiat Modares University, Tehran, Iran
}

\begin{abstract}
Heavy metals are stable and persistent pollutants of the environment, and can cause both natural and anthropogenic pollution in the environment. Therefore, they are regarded as a serious risk for survival of living organisms. In order to reduce environmental problems of these metals, we need to identify natural and anthropogenic resources of them. Indeed, identifying the risk factors and awareness of the amount and effects of pollutants on the one hand, and accurate ranking of the polluting units on the other are essential steps for proper evaluation and timely and appropriate response to these risks, resulting in reduced damage due to them. The purpose of this study is to identify potential pollution sources of heavy metals of mercury, arsenic, lead, cadmium and chromium in Zanjan Province of Iran and their sampling, in order to present an index for ranking polluting units using appropriate scientific approaches like multi criteria decision making for a more accurate and quantitative assessment of risks and planning response to them in due time. The results of this study indicate that among 26 sites sampled, Mineral Processing Corporation of Iran is the most critical place of environmental risk in Zanjan province.
\end{abstract}

Keywords: Heavy Metals, Risk Assessment, Multi Criteria Decision Making (MCDM), Zanjan Province

\section{Introduction}

Heavy metals are natural constituents of the earth crust, but human activities disturb the geochemical and biochemical cycle of equilibrium of these metals, causing their release in the environment (Prasad, 2004 and Sengupta, 2002).

Risk assessment is one of the main steps in risk management, and ranking of risks in place is an important part of risk assessment. Because of timing, financial and other constraints in response and simultaneous reaction to all risks, ranking greatly helps in successful implementation of the risk management process by enabling timely and correct response to them to provide useful guidelines (Azar and Rajabzadeh, 2002). The goal of ranking the different sites for risk of various pollutants is addressing the most important ones given the limited resources. Regarding the fact that multi attribute decision making methods are recognized as useful tools in prioritizing the numerous options, in this paper the use of SAW (Simple Additive Weighted) method as part of MADM was evaluated in ranking the samples having the risk of heavy metals contamination in various parts of Zanjan Province.

According to the type, quality of criteria, desired options, principles and concepts of risk assessment, the values obtained for the weight attribute or final score can be used as indicators of pollution risk from heavy metals. The higher this attribute for a specific location where the sampling has been done, the more critical the heavy metal contamination of this location and the higher the risk. The obtained attribute can be a criterion for evaluation of risk to critically consider the various regions and use it for ranking them. Through the analyses, it can be easily seen that more accurate scientific comparisons of various regions has been enabled. 
Table 1. Primary results of sampling of natural and anthropogenic pollution sources (Analysis results of waste water, effluent and solid waste samplings are in terms of ppm, ppm and $\mathrm{mg} / \mathrm{kg}$, respectively)

\begin{tabular}{|c|c|c|c|c|c|c|c|}
\hline Sampling Points & Code & $\mathrm{Cd}$ & $\mathrm{Cr}$ & $\mathrm{Pb}$ & $\mathrm{Hg}$ & $\mathrm{As}$ & Type \\
\hline Dandi river & $\mathrm{A} 1$ & 0.007 & 0.062 & 0.081 & N.D. & 0.130 & Wastewater \\
\hline$\ldots$ & $\ldots$ & $\ldots$ & $\ldots$ & $\ldots$ & $\ldots$ & $\ldots$ & $\ldots$ \\
\hline Mahneshan river & $\mathrm{A} 8$ & 0.000 & N.D. & 0.038 & N.D. & 0.009 & Wastewater \\
\hline Sayna of Abhar & $\mathrm{F} 1$ & 0.002 & N.D. & 0.016 & N.D. & 0.008 & Effluent \\
\hline Refinery of industrial town no. 1 & $\mathrm{F} 2$ & 0.006 & 0.011 & 0.010 & N.D. & 0.008 & Effluent \\
\hline Stilasa of Zanjan & $\mathrm{P} 1$ & 405.133 & 10.875 & 87.400 & N.D. & N.D. & Solid waste \\
\hline$\ldots$ & $\ldots$ & $\ldots$ & $\ldots$ & $\ldots$ & $\ldots$ & $\ldots$ & $\ldots$ \\
\hline Nickel-cobalt cake dump of faravari & $\mathrm{P} 16$ & 6063.840 & 38.720 & 3207.300 & N.D. & 171.875 & Solid waste \\
\hline
\end{tabular}

\section{Materials and Methods}

\section{The Region Under Study}

For the project to be comprehensive, it was attempted to consider sampling both natural and anthropogenic sources of pollution. The sources were selected and determined based on field studies, conversation and communication with the experts based on importance and the effective key role of each of the sources.

In this province, out of 101 sites considered for sampling (including natural and anthropogenic sampling sites), it was possible to sample only 26 sites, of which the results are presented in Tables 1 and 2 (18 anthropogenic and 8 natural pollutant samples).

\section{Sampling, Preparation and Measurement Operations}

The USGS sampling standard was used for sampling the liquid (wastewater and effluent) and solid (solid waste) samples of the various samples identified (Carr and Neary, 2008). For liquid samples, pH was measured, and if higher than 7, dilute nitric acid was used to avoid likely precipitates or return of the sample to liquid phase. The aqueous samples were then filtered and transferred to laboratory in $250 \mathrm{ml}$ polyethylene containers for analysis. After drying, the solid and sludge samples were grinded, and the materials passing the 200 mesh were digested before feeding into the measuring instrument. In the laboratory, to measure the concentration of metals, ICP instrument was used with measuring precision in $\mathrm{ppb}$ level.

\section{SAW Method and Its Application to Elevate the Data}

This is one of the most widely used methods in MADM, so that in this method, assuming the $\mathrm{W}$ vector (index importance weight), the score of each choice (A) is calculated as follows (Azar and Rajabzadeh, 2002):

$A \quad\left[\frac{z_{1}, w_{1} w_{11}}{z_{1} w_{1}}\right\}$

$\mathrm{r}_{\mathrm{ij}}$ represents the specific values of the attribute $\mathrm{j}$ for choice $\mathrm{i}$, and $\mathrm{W}_{\mathrm{j}}$ is the weight or relative importance of attribute $\mathrm{j}$, and these weights are often determined based on expert comments. Therefore, according to ascending adjustment of this attribute (A), the rating will be possible, so that the higher this index for a choice, it will be in a higher rank (close to one).

If $\Sigma^{\prime} \cdot w_{1} \quad 1$, we will have:

$$
\text { A } \quad\left[2, w \cdot r_{11}\right]
$$

As can be seen, the basis of calculating the score of each choice is the total weighted score of each choice based on different criteria. The important point in this method is that the attributes should have similar measures or be dimensionless to be able to compare them. The logic of this central moment's method is similar to the mean, and in fact it is the same as the weighted average method in which the numbers within the matrix are calculated as elements of which the mean has been calculated, and the attribute weight is considered as the weight of these numbers. Therefore, it is necessary to use a method for making dimensionless to orientate the indices in the same direction.

SAW method algorithm is summarized in two main steps. First step: Making the attributes dimensionless using the linear norm by the following equations:

For indices with positive effect $\left(\mathrm{X}_{\mathrm{j}}^{+}\right)$:

$n_{\|} \frac{r_{i 1}}{m a x_{1} \cdot r_{11}} ; \quad$ i $1, \ldots, m$

For indices with negative effect $\left(\mathrm{X}_{\mathrm{j}}^{-}\right)$:

$n_{\|} \frac{\left.\min n_{1} \cdot r_{\| 1}\right)}{r_{\|}}: ; \quad 1, \ldots, n$

Second step: At this stage, Equation 3 (calculation A) is used, and the final weight (score) of each choice is determined.

Assumptions of this technique are as follows (Tzeng and Huang, 2011): The assumption of applying this method is independence of preference and separation of the indicator effects. The overall favourability of the attributes has been assumed capable of separation to 
Table 2. Normalization of data

\begin{tabular}{|c|c|c|c|c|c|c|c|c|c|c|c|c|}
\hline $\begin{array}{l}\text { Index } \\
\text { of Sample }\end{array}$ & $\mathrm{Cd}$ & $\mathrm{Cr}$ & $\mathrm{Pb}$ & $\mathrm{Hg}$ & As & $\begin{array}{l}\text { Index } \\
\text { of Sample }\end{array}$ & $\mathrm{Cd}$ & $\mathrm{Cr}$ & $\mathrm{Pb}$ & $\mathrm{Hg}$ & As & $\mathrm{Cd}$ \\
\hline A1 & 1.0000 & 1.0000 & 0.9000 & 1.0000 & 1.0000 & $\ldots$ & $\ldots$ & $\ldots$ & $\ldots$ & $\ldots$ & $\ldots$ & $\ldots$ \\
\hline$\ldots$ & $\ldots$ & $\ldots$ & $\ldots$ & $\ldots$ & $\ldots$ & P16 & 0.5141 & 0.0374 & 0.3451 & 7E-07 & 0.0106 & 0.5141 \\
\hline A8 & 0.0000 & 0.0001 & 0.4222 & 1.0000 & 0.0692 & $\mathrm{~A} 1$ & 1.0000 & 1.0000 & 0.9000 & 1.0000 & 1.0000 & 1.0000 \\
\hline F1 & 0.3333 & 0.0009 & 1.0000 & 1.0000 & 1.0000 & $\ldots$ & $\ldots$ & $\ldots$ & $\ldots$ & $\ldots$ & $\ldots$ & $\ldots$ \\
\hline F2 & 1.0000 & 1.0000 & 0.6250 & 1.0000 & 1.0000 & A8 & 0.0000 & 0.0001 & 0.4222 & 1.0000 & 0.0692 & 0.0000 \\
\hline $\mathrm{P} 1$ & 0.0343 & 0.0105 & 0.0094 & 7E-07 & $6 \mathrm{E}-10$ & - & - & - & - & - & - & - \\
\hline
\end{tabular}

Table 4. The final score (index A) of options (samples)

\begin{tabular}{|c|c|c|c|c|c|c|c|}
\hline $\begin{array}{c}\text { Sample } \\
\text { Code }\end{array}$ & $\begin{array}{c}\text { Score (Final } \\
\text { Weight) }\end{array}$ & $\begin{array}{c}\text { Partial } \\
\text { Ranking }\end{array}$ & Overall Ranking & $\begin{array}{c}\text { Sample } \\
\text { Code }\end{array}$ & $\begin{array}{c}\text { Score (Final } \\
\text { Weight) }\end{array}$ & Partial Ranking & $\begin{array}{c}\text { Overall } \\
\text { Ranking }\end{array}$ \\
\hline A1 & 0.99000 & 1 & 17 & F2 & 0.96250 & 1 & 18 \\
\hline$\ldots$ & $\ldots$ & $\ldots$ & $\ldots$ & P1 & 0.00376 & 15 & 15 \\
\hline A8 & 0.55610 & 7 & 24 & P15 & 0.20692 & 4 & 4 \\
\hline F1 & 0.81015 & 2 & 25 & P16 & 0.05843 & 8 & 8 \\
\hline
\end{tabular}

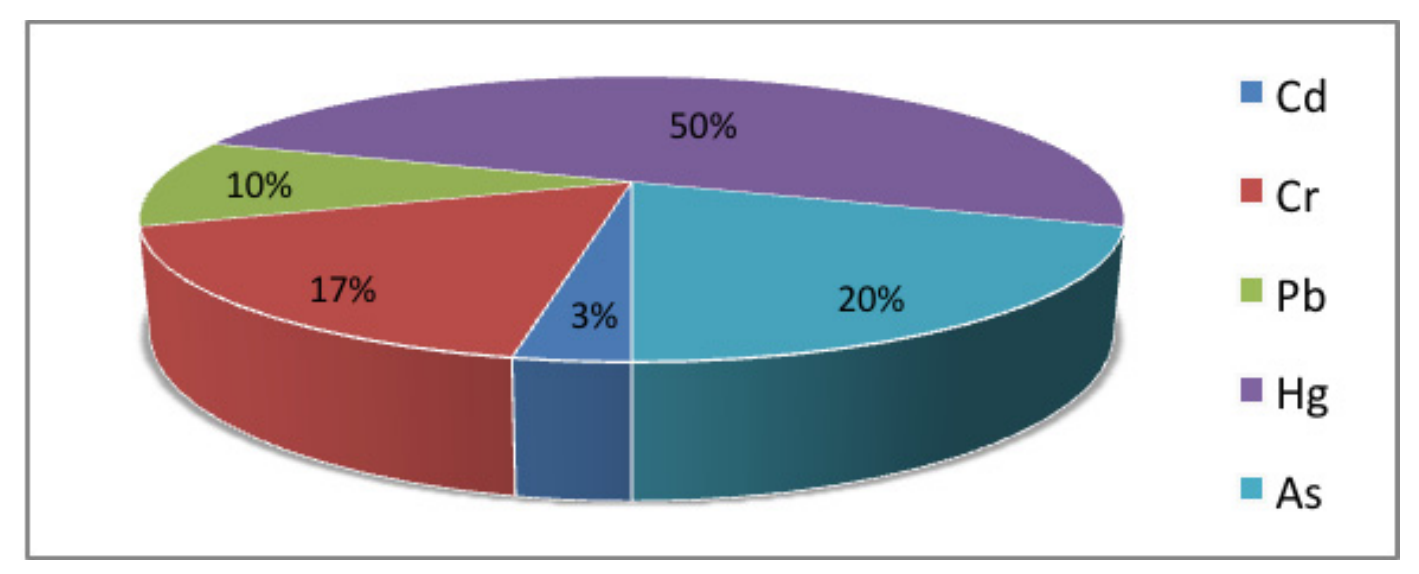

Fig. 1. The relative importance of the indices (the quintet elements).

available favourability of each of the indices, and this way the integrable model is used. The use of SAW is suitable for cases in which the exchange rate among the indices is constant and equals 1. Then, for using this method in ranking the sampled areas, the steps for the respective problem are as follows:

As mentioned, in the first step, based on Equation 3, we normalize the data (Table 3). It is noteworthy that the effect of all the attributes (the amount of the five heavy metals) is positive, and it means that increasing the value of each of these attributes in the samples increases the environmental risk of that site; so, Equation 3 is used to normalize the data.

After that, based on the expert view, relative importance of each of the evaluation attributes (the quintet elements) was determined (Figure 1).

Finally, in order to determine the score (final weight) of each choice (sample), the Equation 2 has been used, and the results are shown in Table 4.

As noted, the ranking can be done based on the obtained weight or final score (index A), and the higher the final score, the more critical the conditions of the sampled site for environmental pollution risk, and the lower the score, the lower the risk. Therefore, ranking is done based on the descending order of this index (partial ranking column). Partial ranking is based on the relative final score of each waste, sewage and water sample separately taken together; the overall ranking results of all samples are shown in comparison to each other in the last column of this table. For example, (P5) for the 
highest score (partial and total grade of 1), in addition to having the most critical risk among solid waste samples, is also introduced as the first rank or the most critical place having the environmental risk among 26 sites being measured.

\section{Conclusion}

In this study, based on the decision making method results of SAW, Mineral Processing Corporation of Iran sample in addition to having the most critical risk among solid waste samples, is also introduced as the first rank or the most critical place having the environmental risk among 26 sites being measured.

\section{Acknowledgements}

The authors wish to thank Modares Environmental Research Center (MERC) of Tarbiat Modarres University and Environmental Organization of Iran for providing the possibility of conducting this research.

\section{References}

Azar, A, Rajabzadeh, A. Applied decision making, $1^{\text {st }}$ Edition, Negahe Danesh Publisher: Tehran, In Persian, 2002.

Carr GM, Neary, JP. Water quality for ecosystem and human health. $2^{\text {nd }}$ Edition, United Nations Environment Programme Global Environment Monitoring System (GEMS)/ Water Programme, 2008.

Prasad MNV. Heavy metal stress in plants: from biomolecules to ecosystems, Springer, 2004.

Sengupta AK. Environmental separation of heavy metals: engineering processes, Lewis Publishers, 2002.

Tzeng, GH, Huang, JJ. Multiple attribute decision making: methods and applications, $1^{\text {st }}$ edition, Chapman and Hall/CRC, 2011. 